\title{
Adult acetonemic vomiting complicated with low body weight in a subject with Mycobacterium avium complex pulmonary disease: A case report
}

\section{Hitomi Tanaka}

Kawasaki Medical School: Kawasaki Ika Daigaku

Takatoshi Anno ( $\sim$ anno-t@umin.ac.jp)

Kawasaki Medical School: Kawasaki lka Daigaku https://orcid.org/0000-0002-7862-3385

\section{Haruka Takenouchi}

Kawasaki Medical School: Kawasaki Ika Daigaku

\section{Fumiko Kawasaki}

Kawasaki Medical School: Kawasaki Ika Daigaku

\section{Katsumi Kurokawa}

Kawasaki Medical School: Kawasaki Ika Daigaku

\section{Niro Okimoto}

Kawasaki Medical School: Kawasaki Ika Daigaku

\section{Koichi Tomoda}

Kawasaki Medical School: Kawasaki Ika Daigaku

Hideaki Kaneto

Kawasaki Medical School: Kawasaki Ika Daigaku

\section{Case Report}

Keywords: Acetonemic vomiting, Low body weight, Adult, Mycobacterium avium complex pulmonary disease, Slight hypoglycemia

Posted Date: July 27th, 2021

DOI: https://doi.org/10.21203/rs.3.rs-713163/v1

License: (c) (1) This work is licensed under a Creative Commons Attribution 4.0 International License. Read Full License 


\section{Abstract}

\section{Background}

Pulmonary diseases often bring about a significant health issue and nutritional disorders. Weight loss and malnutrition are related to the severity of obstructive disorders. Therefore, such patients easily fall into lack of nutritional energy. Acetonemic vomiting is caused by acetonemic syndrome and recently it has been considered that acetonemic vomiting can occur at any age from infancy to adulthood. It is considered that acetonemic vomiting is likely brought about in subjects with low body weight, because stored carbohydrates in the body are reduced and fats are mainly utilized. As the results, large amounts of acetone are produced, which causes nausea and vomiting together with hypoglycemia.

Case presentation

A 79-year-old Japanese woman was brought to an emergency room with symptoms of nausea and vomiting. She was diagnosed as MAC pulmonary disease at the age of 52. Her height, body weight and body mass index (BMI) were $155.4 \mathrm{~cm}, 33.5 \mathrm{~kg}$ and $13.9 \mathrm{~kg} / \mathrm{m}^{2}$, respectively. she had slight hypoglycemia and urinary ketone bodies. Surprisingly, she had been hospitalized four times within one year and her main complaint in every hospitalization were nausea and vomiting. Moreover, at every hospitalization, she had repeated slight hypoglycemia and urinary ketone bodies. Based on such findings, we finally diagnosed her as acetonemic vomiting complicated with low body weight. We started the education and diet therapy for her and after then she has not been hospitalized for one year.

\section{Conclusions}

We should bear in mind that the subjects with pulmonary diseases are often complicated with low body weight and thereby they could have acetonemic vomiting with slight hypoglycemia and ketosis. It is very important that such pulmonary diseases patients with low body weight and repeated nausea and/or vomiting get appropriate education and diet therapy, because their repeated symptoms can be mitigated by such therapy.

\section{Background}

Pulmonary diseases often bring about a significant health issue and nutritional disorders. In addition, nutritional disorders are commonly complicated with various pulmonary diseases, such as chronic obstructive pulmonary disease (COPD) [1], pulmonary tuberculosis [2] and Mycobacterium avium complex (MAC) pulmonary disease [3]. In chronic respiratory failure, it has been pointed out that the complications of nutritional disorders have negative effects on the condition and prognosis. Weight loss is related to the severity of obstructive disorders and subjects with a body mass index (BMI) of less than $20 \mathrm{~kg} / \mathrm{m}^{2}$ was observed in about $30 \%$. 
Acetonemic vomiting is caused by acetonemic syndrome, which is also called as acetonemic vomiting syndrome and cyclic vomiting syndrome, and it is observed in childhood. The median age of onset of symptoms varies from 3.5 to 7 years [4-6]. However, recently it has been considered that acetonemic vomiting can occur at any age from infancy to adulthood [7]. In children, acetonemic vomiting is caused by malnutrition and leads to loss of appetite and frequent vomiting. On the other hand, in adults, acetonemic vomiting can develop when the purine or protein balance is disturbed and ketone bodies levels are increased.

\section{Case Presentation}

A 79-year-old Japanese woman was brought to an emergency room with symptoms of nausea and vomiting. She was diagnosed as MAC pulmonary disease at the age of 52 , and as polymyalgia rheumatic at 73 and rheumatoid arthritis at 75 . She was taking $150 \mathrm{mg} /$ day of rifampicin, $250 \mathrm{mg} /$ day of ethambutol, $400 \mathrm{mg} /$ day of clarithromycin and $5 \mathrm{mg} /$ day of prednisolone for the treatment of MAC pulmonary disease and $3 \mathrm{mg} /$ day of tacrolimus and $100 \mathrm{mg} /$ day of pregabalin for polymyalgia rheumatic and rheumatoid arthritis. She had no remarkable family history. She had no drinking and smoking. Her height, body weight and BMI were $155.4 \mathrm{~cm}, 33.5 \mathrm{~kg}$ and $13.9 \mathrm{~kg} / \mathrm{m}^{2}$, respectively. Her vital signs were as follows: temperature, $36.8^{\circ} \mathrm{C}$; blood pressure, $118 / 62 \mathrm{mmHg}$; heart rate, 84 beats $/ \mathrm{min}$; oxygen saturation, $98 \%$ (room air). Table 1 shows laboratory data in an emergency room. Her infection markers were markedly elevated: white blood cell, 21,460 / $\mu \mathrm{L}$ (neutrophil, $88.5 \%$ ); C-reactive protein, $36.09 \mathrm{mg} / \mathrm{dL}$. Liver and renal function was almost within the normal range: aspartate aminotransferase (AST), $34 \mathrm{U} / \mathrm{L}$; alanine transaminase (ALT), $13 \mathrm{U} / \mathrm{L}$; alkaline phosphatase (ALP), $250 \mathrm{U} / \mathrm{L}$; $\gamma$-glutamyl transpeptidase (Y-GTP), $24 \mathrm{U} / \mathrm{L}$; lactate dehydrogenase (LDH), $215 \mathrm{U} / \mathrm{L}$; creatinine, $0.74 \mathrm{mg} / \mathrm{dL}$; blood urea nitrogen (BUN), $39 \mathrm{mg} / \mathrm{dL}$. In addition, her nutrition-associated data were as follows: plasma glucose, $66 \mathrm{mg} / \mathrm{dL}$; hemoglobin A1c (HbA1c), $6.1 \%$; total cholesterol, $113 \mathrm{mg} / \mathrm{dL}$; total protein, $6.1 \mathrm{~g} / \mathrm{dL}$; albumin, $2.8 \mathrm{~g} / \mathrm{dL}$; cholinesterase, $125 \mathrm{U} / \mathrm{L}$. Moreover, her urinary test showed elevated urinary ketone body (2+), and serum ketone body concentrations were high as follows: total ketone body, 3,107.6 $\mu \mathrm{mol} / \mathrm{L}$; acetoacetate, 1,032.7 $\mu \mathrm{mol} / \mathrm{L} ; \beta$-hydroxybuterate, $2074.9 \mu \mathrm{mol} / \mathrm{L}$. 
Table 1

Laboratory data in an emergency room in this subject

\begin{tabular}{|c|c|c|c|c|c|}
\hline Variable & Result & $\begin{array}{l}\text { Reference } \\
\text { range }\end{array}$ & Variable & Result & $\begin{array}{l}\text { Reference } \\
\text { range }\end{array}$ \\
\hline Blood biochemistry & & & Peripheral blood & & \\
\hline Total protein $(\mathrm{g} / \mathrm{dL})$ & 6.1 & $6.6-8.1$ & White blood cells $(/ \mu \mathrm{L})$ & 21460 & $3300-8600$ \\
\hline Albumin (g/dL) & 2.8 & $4.1-5.1$ & Neutrophil (\%) & 88.5 & $52.0-80.0$ \\
\hline Globulin (g/dL) & 3.3 & $2.2-3.4$ & $\begin{array}{l}\text { Red blood cells }\left(\times 10^{4} /\right. \\
\mu \mathrm{L})\end{array}$ & 439 & $386-492$ \\
\hline $\begin{array}{l}\text { Total bilirubin } \\
\text { (mg/dL) }\end{array}$ & 0.8 & $0.4-1.5$ & Hemoglobin (g/dL) & 12.0 & $11.6-14.8$ \\
\hline AST (U/L) & 34 & $13-30$ & Hematocrit (\%) & 37.5 & $35.1-44.4$ \\
\hline ALT (U/L) & 13 & $7-23$ & Platelets $\left(\times 10^{4} / \mu \mathrm{L}\right)$ & 22.3 & $15.8-34.8$ \\
\hline LDH (U/L) & 215 & $124-222$ & Diabetes and Dyslipider & markers & \\
\hline ALP (U/L) & 250 & $106-322$ & $\begin{array}{l}\text { Plasma glucose } \\
(\mathrm{mg} / \mathrm{dL})\end{array}$ & 66 & \\
\hline Y-GTP (U/L) & 24 & $9-32$ & Hemoglobin A1c (\%) & 6.1 & $4.9-6.0$ \\
\hline BUN (mg/dL) & 39 & $8-20$ & $\begin{array}{l}\text { Total cholesterol } \\
(\mathrm{mg} / \mathrm{dL})\end{array}$ & 113 & $142-248$ \\
\hline Creatinine (mg/dL) & 0.74 & $0.46-0.79$ & $\begin{array}{l}\text { Total ketone body } \\
(\mu \mathrm{mol} / \mathrm{L})\end{array}$ & 3107.6 & $0.0-130.0$ \\
\hline $\begin{array}{l}\text { Cholinesterase } \\
(\mathrm{U} / \mathrm{L})\end{array}$ & 125 & $201-421$ & Acetoacetate $(\mu \mathrm{mol} / \mathrm{L})$ & 1032.7 & $0.0-55.0$ \\
\hline Uric acid (mg/dL) & 8.7 & $2.6-5.5$ & $\begin{array}{l}\beta \text {-Hydroxybuterate } \\
(\mu \mathrm{mol} / \mathrm{L})\end{array}$ & 2074.9 & $0.0-85.0$ \\
\hline $\begin{array}{l}\text { Creatine Kinase } \\
(\mathrm{U} / \mathrm{L})\end{array}$ & 49 & $41-153$ & Urinary test & & \\
\hline Amylase (U/L) & 264 & $44-132$ & Urinary $\mathrm{pH}$ & 5.5 & $5.0-7.5$ \\
\hline CRP (mg/dL) & 36.09 & $<0.14$ & Urinary protein & $1+$ & - \\
\hline Sodium (mEq/L) & 140 & $138-145$ & Urinary sugar & - & - \\
\hline Potassium (mEq/L) & 3.9 & $3.6-4.8$ & Urinary ketone body & $2+$ & - \\
\hline Chloride (mEq/L) & 99 & $101-108$ & Urinary bilirubin & - & - \\
\hline
\end{tabular}

Abbreviation: AST, aspartate aminotransferase; ALT, alanine aminotransferase; $L D H$, lactate dehydrogenase; ALP, alkaline phosphatase; $\gamma$-GTP, $\gamma$-glutamyl transpeptidase; BUN, blood urea nitrogen; CRP, C-reactive protein 


\begin{tabular}{|c|c|c|c|c|c|}
\hline Variable & Result & $\begin{array}{l}\text { Reference } \\
\text { range }\end{array}$ & Variable & Result & $\begin{array}{l}\text { Reference } \\
\text { range }\end{array}$ \\
\hline Calcium (mg/dL) & 7.9 & $8.8-10.1$ & Urinary blood & $2+$ & - \\
\hline \multicolumn{6}{|c|}{$\begin{array}{l}\text { Abbreviation: AST, aspartate aminotransferase; ALT, alanine aminotransferase; LDH, lactate } \\
\text { dehydrogenase; ALP, alkaline phosphatase; } \mathrm{Y} \text {-GTP, Y-glutamyl transpeptidase; BUN, blood urea } \\
\text { nitrogen; CRP, C-reactive protein }\end{array}$} \\
\hline
\end{tabular}

After admission, we started antibiotics therapy ( $13.5 \mathrm{~g} /$ day of tazobactam), because her infection markers were markedly elevated. Her fever was immediately improved next day (its peak was $37.5^{\circ} \mathrm{C}$ ) and her infection markers were decreased (white blood cell, 5,260 / $\mathrm{LL}$; C-reactive protein, $5.42 \mathrm{mg} / \mathrm{dL}$ ). Surprisingly, she had been hospitalized four times within one year. Therefore, we checked details of her laboratory data during the period of hospitalization. Her body weight was decreased to under $35.0 \mathrm{~kg}$ about 1 years ago. Her main complaint in every hospitalization were nausea and vomiting, although she was complicated with MAC pulmonary disease. Moreover, at every hospitalization, she had slight hypoglycemia and urinary ketone bodies (Fig. 1). Based on such findings, we finally diagnosed her as acetonemic vomiting complicated with low body weight. In addition, her low body weight was caused by MAC pulmonary disease. We started the education and diet therapy for her (total 1,500 kcal/day (about $30 \mathrm{kcal}$ per ideal body weight) and without skipping meals including carbohydrate), and after then she was not hospitalized for one year.

\section{Discussion And Conclusions}

Herein, we report a case of adult acetonemic vomiting complicated with low body weight in a subject with MAC pulmonary disease. Pulmonary diseases including MAC pulmonary disease often cause low body weight and malnutrition. Therefore, such patients easily fall into lack of nutritional energy. On the other hand, it is considered that acetonemic vomiting is likely brought about in subjects with low body weight, because stored carbohydrates in the body are reduced and fats are mainly utilized. As the results, large amounts of acetone are produced, which causes nausea and vomiting together with hypoglycemia.

Acetonemic vomiting is induced in subjects with acetonemic syndrome, especially in childhood. The median age of onset of symptoms varies from 3.5 to 7 years and the amounts of acetone and acetoacetic acid are increased in children with acetonemic syndrome. As the mechanisms of protein catabolism, carbohydrates and fats are associated with tricarboxylic acid (TCA) cycle under normal physiological conditions. Ketosis is mainly induced under fasting state or excessive consumption of protein and fatty foods. In addition, under relative or absolute deficiency of carbohydrate conditions, lipolysis is facilitated and energy in the body is supplemented. As the result, ketone bodies are synthesized from acetyl coenzyme A in the body with increased lipolysis. It has been shown recently that acetonemic vomiting can be brought about even in adults when the purine or protein balance is disturbed and ketone bodies levels are increased. Our patient suffered from MAC pulmonary disease for a long time, and such condition could easily lead to energy deficiency with low body weight. Therefore, we think that she suffered from relapsing acetonemic vomiting, although she was an adult. The current case 
report shows that when the subjects with pulmonary disease and low body weight suffer from symptoms with nausea and vomiting, we should think the possibility of acetonemic vomiting even in adults.

There are several strengths in this case report. First, the frequency of pulmonary diseases complicated with weight loss was about $30 \%$ of total chronic pulmonary diseases. Such patients have a predisposition caused by acetonemic vomiting. Therefore, when the subjects with pulmonary disease and low body weight suffer from symptoms with nausea and vomiting, we should think the possibility of acetonemic vomiting even in adults. Second, in our patient, the symptom of nausea and vomiting disappeared after diet therapy with about $30 \mathrm{kcal}$ per ideal body weight and without skipping meals including carbohydrate. This is the most important point because repeated symptoms of nausea and vomiting are improved with appropriate education and diet therapy in the subjects with adult acetonemic vomiting induced by low body weight and pulmonary diseases. There are also several limitations in this report. She was taking $5 \mathrm{mg}$ /day of prednisolone for the treatment of MAC pulmonary disease at least for 5 years, although dose of prednisolone was from $5 \mathrm{mg} /$ day to $10 \mathrm{mg} /$ day. Therefore, there is a possibility she suffered from relative adrenal insufficiency. In general, many cases of relative adrenal insufficiency are complicated with fatigue, loss of appetite, weight loss, hypotension and hyponatremia, hypoglycemia, or relative hypereosinophilia. Our patient had nausea, vomiting, loss of appetite and weight loss with therapy of prednisolone. In addition, although she showed hypoglycemia around $40-70 \mathrm{mg} / \mathrm{dL}$, she did not show hypotension and hyponatremia. Therefore, we did not consider she was under relative adrenal insufficiency. We considered her hypoglycemia was caused by low body weight, although she had slightly hypoglycemia.

We should bear in mind that the subjects with pulmonary diseases including MAC pulmonary disease are often complicated with low body weight and thereby they could have acetonemic vomiting with slight hypoglycemia and ketosis. In addition, this case report clearly indicates that we should know the possibility of acetonemic vomiting not only in children but also even in adults, especially when some underweight subjects have repeated nausea and/or vomiting. Moreover, it is very important for such patients to get appropriate education and diet therapy, because their repeated symptoms can be mitigated by such therapy.

\section{List Of Abbreviations}

COPD, chronic obstructive pulmonary disease; MAC, Mycobacterium avium complex, BMI, body mass index; AST, aspartate aminotransferase; ALT, alanine transaminase; ALP, alkaline phosphatase; Y-GTP, Yglutamyl transpeptidase; LDH, lactate dehydrogenase; BUN, blood urea nitrogen; TCA, tricarboxylic acid

\section{Declarations}

\section{Ethics approval and consent to participate:}

Not applicable 
Consent for publication:

Written informed consent for the publication of this case report was obtained from the patient.

\section{Availability of data and material:}

Not applicable

\section{Competing interests:}

We do not have any potential conflicts of interest relevant to this article.

\section{Funding:}

The authors declare that there is no funding associated with this manuscript.

\section{Authors' contributions:}

Hi.T and T.A., researched data and wrote the manuscript. Hu.T., F.K. and K.K. researched data and contributed to the discussion. N.O., K.T. and H.K. reviewed the manuscript.

All authors have read and approved the manuscript.

\section{Acknowledgements:}

Not applicable

\section{References}

1. Ho SC, Wang JY, Kuo HP, Huang CD, Lee KY, Chuang HC, et al. Mid-arm and calf circumferences are stronger mortality predictors than body mass index for patients with chronic obstructive pulmonary disease. Int J Chron Obstruct Pulmon Dis. 2016;11:2075-80.

2. Onwubalili JK. Malnutrition among tuberculosis patients in Harrow, England. Eur J Clin Nutr. 1988;42:363-6.

3. Morimoto K, Yoshiyama T, Kurashima A, Sasaki Y, Hoshino Y, Yoshimori K, et al. Nutritional indicators are correlated with the radiological severity score in patients with Mycobacterium avium complex pulmonary disease: a cross-sectional study. Intern Med. 2014;53:397-401.

4. Fitzpatrick E, Bourke B, Drumm B, Rowland $M$. The incidence of cyclic vomiting syndrome in children: population-based study. Am J Gastroenterol. 2008;103:991-5. quiz 996.

5. Lin YP, Ni YH, Weng WC, Lee WT. Cyclic vomiting syndrome and migraine in children. J Formos Med Assoc. 2011;110:382-7.

6. Raucci U, Borrelli O, Di Nardo G, Tambucci R, Pavone P, Salvatore S, et al. Cyclic Vomiting Syndrome in Children. Front Neurol. 2020 Nov;2:11: 583425. 
7. Venkatesan T, Prieto T, Barboi A, Li B, Schroeder A, Hogan W, et al. Autonomic nerve function in adults with cyclic vomiting syndrome: a prospective study. Neurogastroenterol Motil. 2010; 22: 1303-7130, e339.

\section{Figures}

hospitalization

1 st.

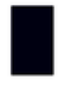

Plasma glucose $(\mathrm{mg} / \mathrm{dL})$

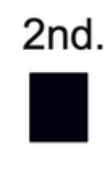

49 3rd. 4th.

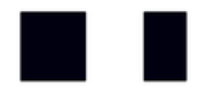

Figure 1 5th.

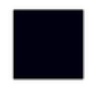

66 Urinary ketone body

(1+)

$(-) \quad(-)$

$\begin{array}{lc}\mathrm{BW}(\mathrm{kg}) & 34.6 \\ \mathrm{BP}(\mathrm{mmHg}) & 118 / 60 \\ \mathrm{WBC}(/ \mu \mathrm{L}) & 8910 \\ \mathrm{Eosino}(\%) & 2.0 \\ \mathrm{Na}(\mathrm{mEq} / \mathrm{L}) & 139\end{array}$
(2+)

$(-)$

$(-)$

$(-)$

34.5

$117 / 61$

18180

0.0

141
$67 \quad 75$

(1+) (1+)
(2+)

$(-) \quad(-) \quad(-)$

33.5

$118 / 62$

21460

0.0

140

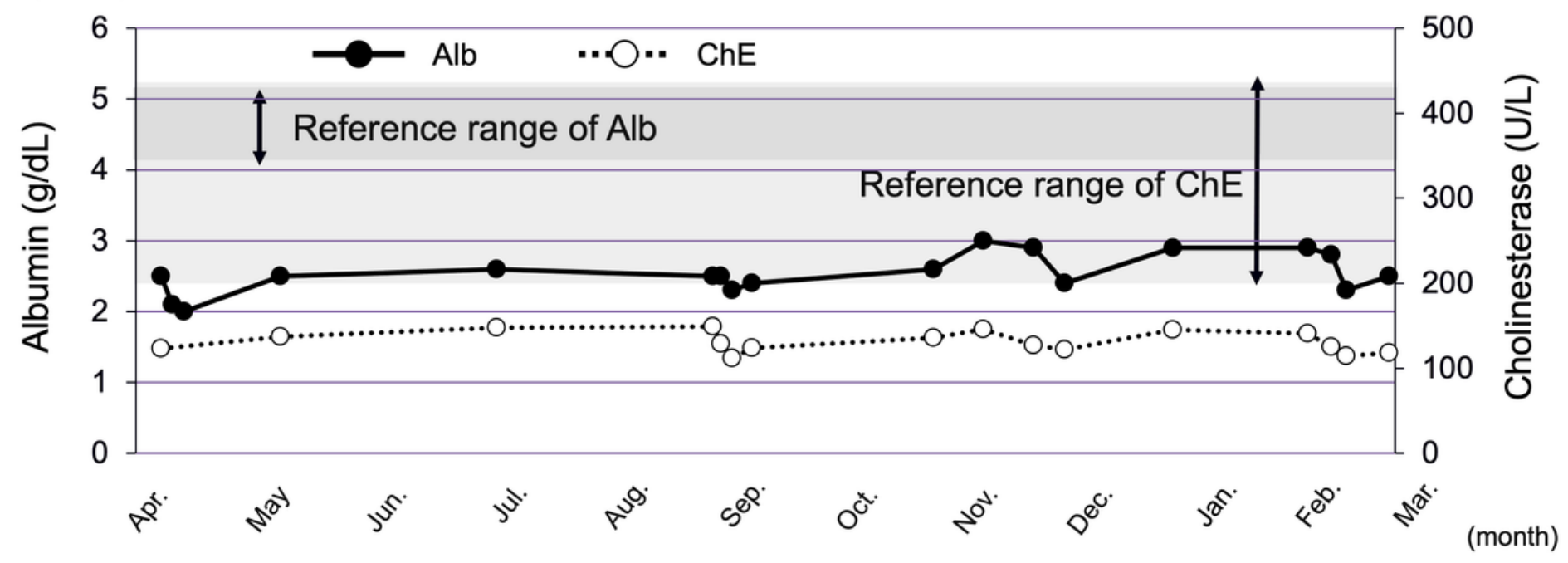

Figure 1

Time course of clinical parameters in this subject. This patient underwent 5 times of hospitalization including at this admission for only 1 year. She was under low nutrition conditions (low albumin and cholinesterase levels). In addition, in every hospitalization, she suffered from nausea and vomiting together with hypoglycemia and ketosis. BW, body weight; BP, blood pressure; WBC, white blood cell; Eosino, eosinophil; Na, sodium; Alb, albumin; ChE, cholinesterase

\section{Supplementary Files}


This is a list of supplementary files associated with this preprint. Click to download.

- Hi.T.NutritionJournalCAREchecklistEnglish2013.pdf.docx 